\title{
A OMnipresenÇA do PODER EM Michel Foucault
}

\author{
[ POWER OF OMNIPRESENCE IN Michel Foucault ]
}

Resumo: O poder é omnipresente em Michel Foucault, isso é dito textualmente. Resta, contudo, analisar o que significa e se isso implicaria necessariamente em uma avaliação negativa sobre o fenômeno. Para isso, iremos identificar alguns elementos importantes na obra do autor, tais como a superação da concepção jurídico-discursiva do poder, a análise de algumas considerações gerais que Foucault faz sobre as relações de poder, o conceito de "anarqueologia" e a sugestão de uma filosofia analítica da política, em termos de contra-poder. Desta forma, buscamos defender que reconhecer a omnipresença do poder seria, na verdade, detectar uma característica essencial que nos permite lidar melhor com o fato de que estamos sempre em processos relacionais com o poder, mas que isso, ao invés de nos subjugar completamente, permite que sejamos livres.

Palavras-chave: poder; omnipresença; anarqueologia; liberdade
Daniel Luis Cidade Gonçalves * Universidade do Estado de Santa Catarina, Brasil
ABSTRaCT: Power is omnipresent in Michel Foucault, this is said textually. It remains, however, to analyze what it means and whether this would necessarily imply a negative evaluation of the phenomenon. For this, we will identify some important elements in the author's work, such as overcoming the legaldiscursive conception of power, the analysis of some general considerations that Foucault makes about power relations, the concept of "anarchaelogy" and the suggestion of a analitycal philosophy of politics in terms of counter-power. In this way, we seek to argue that recognizing the omnipresence of power would actually detect an essential feature that allows us to deal better with the fact that we are always in processes related to power, but that, rather than completely subjugating ourselves, it allows us to be free.

KEYWORDS: power; omnipresence; anarchism; freedom

\section{SUPERANDO A CONCEPÇÃo JURÍDICO-DISCURSIVA DE PODER}

$\mathrm{N}$ o primeiro volume de História da sexualidade, intitulado $A$ vontade de saber, Foucault defende que foi necessário a instauração de uma série de mecanismos de poder para suprir a enorme demanda de verdade levantada pelo Ocidente. Neste contexto, quase como se estivesse se recusando a jogar este jogo e alimentar ainda mais esta demanda, Foucault nega que almeja construir uma teoria do poder. Antes disso, o filósofo francês prefere entender suas considerações sobre o conceito como uma "analítica do poder", na medida em que não tem como objetivo explicar em que consiste o "Poder", mas explicitar suas relações e fornecer os

* Doutor em Filosofia Política e Ética pela pela Universidade Federal de Santa Catarina. Professor substituto na Fundação Universidade Regional de Blumenau (FURB); Universidade do Estado de Santa Catarina (UDESC) e Instituto Federal Catarinense (IFC). m@ilto: daniel.cidade@gmail.com 
instrumentos necessários para analisá-lo adequadamente. Para isso, seria necessário uma espécie de "tábula rasa" que nos permitisse uma libertação daquilo que o autor intitula "concepção jurídico-discursiva" do poder.

De certa forma, a concepção jurídico-discursiva do poder se mantém no nível do senso comum. A ideia de que o poder é aquilo que proíbe, interdita, diz "não", reduz o objeto a um regime binário que só fala a linguagem do permitido ou proibido. Uma forma geral de poder que assume o aspecto do direito e da lei, do lícito e do ilícito, da transgressão e do castigo. Em suma, na concepção jurídico-discursiva, o poder é aquilo que possui legitimidade para dizer àqueles sob o qual se exerce, o que podem ou não fazer. É por isso que também podemos chamar esta concepção de "poder soberano".

Poder soberano na medida em que encontramos nesta concepção tradicional o privilégio teórico da soberania e da lei. Sob esta concepção de poder, buscamos a instância privilegiada que transfere ao soberano a legitimidade de ditar a lei se se fazer obedecer. Importante ressaltar que o soberano pode ser um único indivíduo (monarquia), um pequeno grupo de indivíduos (aristocracia) ou toda a população (democracia). Para Foucault, o grande desafio é superar esta concepção em busca de uma maneira de operacionalizar nossa compreensão do fenômeno que esteja mais de acordo com a complexidade presente nas relações de poder contemporâneas.

Foucault alega de maneira evidentemente metafórica que devemos "cortar a cabeça do rei" em busca de uma nova concepção de poder que nos permita pensar "o sexo sem lei e o poder sem rei" (FOUCAULT, 1988a, p. 87). Lembrando que no momento em que tais palavras são ditas, Foucault está falando a partir do contexto de uma história da sexualidade. Aqui iremos deixar de lado as especificidades de tal análise para nos concentrar na experiência foucaultiana de prescindir das ferramentas analíticas tradicionais para construir outros instrumentos conceituais que nos permitam lidar com o fenômeno de maneira mais eficiente. Dessa forma, nesse primeiro momento, iremos ressaltar o caráter microfísico do poder e sua interdependência com o saber.

Segundo o filósofo francês, devemos entender o poder muito mais em seu aspecto microfísico do que em seu aspecto centralizado (presente na visão soberana). Dessa forma, faria mais sentido falarmos em "relações de poder" do que em "Poder" com P maiúsculo, como se ele fosse uma substância que emana de algum lugar, ou algo que pertence a alguém e pode ser transferido. É nesse sentido que podemos falar de uma "microfísica do poder" em Michel Foucault. Ninguém possui o poder como uma propriedade. Tudo o que temos são inúmeros indivíduos organizando manobras, criando técnicas e estratégias para influenciar e até mesmo governar as ações humanas. $\mathrm{O}$ poder, nesse contexto, é entendido como uma estratégia, uma luta constante, que pode sim encontrar pontos de estabilidade, mas que, por sua vez, não lhe fornece nenhum privilégio epistemológico. Nas palavras do autor:

Temos em suma que admitir que esse poder se exerce mais que se possui, que não é o "privilégio" adquirido ou conservado da classe dominante, mas o efeito de conjunto de suas posições estratégicas - efeito manifestado e às vezes reconduzido pela posição dos que são dominados. (FOUCAULT, 1987, p. 26).

A partir desta constatação, podemos entender melhor a interdependência que as relações de poder possuem para com as relações de saber. Para isso, comentaremos a seguinte passagem do autor:

Seria talvez preciso também renunciar a toda uma tradição que deixa imaginar que só pode haver saber onde as relações de poder estão suspensas e que o saber só pode desenvolver-se fora de suas injunções, suas exigências e seus interesses. Seria talvez preciso renunciar a crer que o poder enlouquece e que em compensação a renúncia ao poder é uma das condições para que se possa tornar- 
se sábio. Temos antes que admitir que o poder produz saber (e não simplesmente favorecendo-o porque o serve ou aplicando-o porque é útil); que poder e saber estão diretamente implicados; que não há relação de poder sem constituição correlata de um campo de saber, nem saber que não suponha e não constitua ao mesmo tempo relações de poder. Essas relações de "poder-saber" não devem então ser analisadas a partir de um sujeito do conhecimento que seria ou não livre em redação ao sistema do poder; mas é preciso considerar ao contrário que $o$ sujeito que conhece, os objetos a conhecer e as modalidades de conhecimentos são outros tantos efeitos dessas implicações fundamentais do poder-saber e de suas transformações históricas. Resumindo, não é a atividade do sujeito de conhecimento que produziria um saber, útil ou arredio ao poder, mas o podersaber, os processos e as lutas que o atravessam e que o constituem, que determinam as formas e os campos possíveis do conhecimento. (FOUCAULT, 1987, p. 26/27).

Foucault nos convida a renunciar à tradição ocidental platônica que entende o poder e o saber como coisas completamente distintas e até mesmo irreconciliáveis. $\mathrm{O}$ poder produz saber e vice-versa. A história de um grande poder traz consigo a história de inúmeras relações de saber bem-sucedidas que conferem legitimidade ao mesmo, permitindo assim sua estabilidade. Mudando a direção do vetor, a história de um grande saber também possui inúmeras estratégias de poder que permitiram sua afirmação perante outras formas de saber concorrentes. Importante, todavia, ressaltar o papel central que o sujeito assume nestas relações que podemos chamar de relações de podersaber.

Para Foucault, o sujeito não consiste em um ser que possui uma essência prévia que determina sua subjetividade. Embora possua inúmeras discordâncias com Sartre, Foucault encontra-se entre os pensadores para quem "a existência precede a essência". Neste sentido, o sujeito é o resultado de um organismo biológico inserido em contextos diversos, todos eles com inúmeras relações de saber-poder conflitantes que, por sua vez, exercem um papel fundamental na constituição de sua subjetividade. O sujeito é sempre fruto do meio em que se encontra, das relações em que está inserido. Podemos dizer que Foucault analisa o poder para compreender o sujeito.

Eu gostaria de dizer, antes de mais nada, qual foi o objetivo do meu trabalho nos últimos vinte anos. Não foi analisar o fenômeno do poder nem elaborar os fundamentos de tal análise. Meu objetivo, ao contrário, foi criar uma história dos diferentes modos pelos quais, em nossa cultura, os seres humanos tornaram-se sujeitos. (FOUCAULT, 1995, p. 231).

Contudo, se podemos dizer que o objetivo de Foucault foi entender como os seres humanos tornaram-se sujeitos, também podemos dizer que isso o levou a analisar muito mais as formas de poder do que as inúmeras formas de sujeitos que encontramos mundo afora. Isto porque o interesse de Foucault é muito mais baseado no processo em que nos tornamos sujeitos do que na subjetividade adquirida através destes processos. As relações de poder-saber são o que possibilitam tais acontecimentos. Compreendê-las é o primeiro momento para que possamos compreender melhor nós mesmos. Neste sentido, apresentamos uma "definição" provisória do que seria o poder para o autor:

Parece-me que se deve compreender o poder, primeiro, como a multiplicidade de correlações de forças imanentes ao domínio onde se exercem e constitutivas de sua organização; o jogo que através de lutas e afrontamentos incessantes as transforma, reforça, inverte; os apoios que tais correlações de força encontram umas nas outras, formando cadeias ou sistemas ou ao contrário, as defasagens e contradições que as isolam entre si; enfim, as estratégias em que se originam e cujo esboço geral ou cristalização institucional toma corpo nos aparelhos estatais, 
na formulação da lei, nas hegemonias sociais. A condição de possibilidade do poder, em todo caso, o ponto de vista que permite tornar seu exercício inteligível até em seus efeitos mais "periféricos" e, também, enseja empregar seus mecanismos como chave de inteligibilidade do campo social, não deve ser procurada na existência primeira de um ponto central, num foco único de soberania de onde partiriam formas derivadas e descendentes; é o suporte móvel das correlações de força que, devido a sua desigualdade, induzem continuamente estados de poder, mas sempre localizados e instáveis. (FOUCAULT, 1988a, p. 88/89).

Dizer que o poder consiste em uma multiplicidade de correlações de forças e que tais forças se encontram imanentes ao domínio em que se exercem, consiste em dizer, em outras palavras, que o poder é uma instância difusa em inúmeros os contextos possíveis e que sua posição exerce um caráter interno e externo à constituição da própria organização dos contextos. É a partir das relações de poder que tais contextos são possíveis, mas as próprias relações de poder só são possíveis a partir de tais contextos. Na imanência, encontramos uma interdependência quase paradoxal e certamente cíclica entre as relações de poder que permitem a existência do contexto em que se encontram inseridas e o contexto que permite a existência de tais relações. A "organização" que podemos detectar é póstuma à existência nua e crua deste diálogo.

Mas o que seriam estes "contextos"? As instituições estatais, as leis, os próprios sujeitos. Tudo aquilo que é constituído pelas relações de poder-saber. Toda significação detectável, toda interpretação possível. A própria soberania, os valores morais e a inteligibilidade do campo social. É neste sentido que a continuação da citação anterior nos alerta para uma omnipresença do poder:

Onipresença do poder: não porque tenha o privilégio de agrupar tudo sob sua invencível unidade, mas porque se produz a cada instante, em todos os pontos, ou melhor, em toda relação entre um ponto e outro. O poder está em toda parte; não porque englobe tudo e sim porque provém de todos os lugares. (FOUCAULT, 1988a, p. 88/89).

Tomaremos esta omnipresença do poder - em seu caráter imanente às relações que permitem sua existência e só existe por causa dele - como fio-condutor para falarmos um pouco mais sobre algumas características do poder e, logo em seguida, debater dois posicionamentos do autor, na medida em que o mesmo propõe uma "anarqueologia" enquanto posição político-epistemológica e uma "filosofia analítica da política" enquanto posição político-estratégica.

\section{CONSIDERAÇõES GERAIS SOBRE O PODER}

Ainda em $A$ vontade de saber, Foucault faz algumas considerações bastante importantes, tendo o intuito de superar a concepção jurídico-discursiva do poder e explicitar melhor sua nova metodologia para analisar o fenômeno. Consideramos que estas considerações são bastante importantes e reforçam a omnipresença do poder como um fio condutor para irmos em direção a algumas conclusões estratégicas acerca de nosso período contemporâneo.

Em primeiro lugar, a despeito da concepção jurídico-discursiva de poder, presente no poder soberano, para Foucault, o poder não é algo que se adquire. O jogo da soberania na qual o poder é visto como algo que pertence ou não pertence à alguns, torna-se anacrônico na concepção foucaultiana. A visão de poder do autor o entende muito mais como uma estratégia do que como uma propriedade. Dizer que ninguém "detém" o poder significa dizer que tudo o que podemos fazer é articular estratégias de maneira consciente ou inconsciente - para exercer efeitos de poder, dadas as relações 
vigentes e a nossa capacidade de articulação.

A dimensão do saber torna-se evidente. A legitimidade de qualquer poder (ou a falta dela), consiste sempre em um discurso que se faz convincente ou não. Existe aqui um rompimento com qualquer tentativa de buscar algum tipo de transcendência para o fenômeno. O poder não emana de Deus ou da autoridade concedida por ele, tampouco de uma natureza teleológica cuja finalidade pode ser lida em suas entrelinhas. As relações de poder são fatos concretos que se impõem aos indivíduos, sempre dentro de um jogo estratégico e fluído (em maior ou menor grau), cuja potência será tanto maior quanto sua capacidade de convencimento, mas também, cuja capacidade de convencimento será tanto maior quanto sua potência.

Em segundo lugar, para Foucault, as relações de poder não se encontram em posição de exterioridade para com outros tipos de relações. A interdependência entre o saber e o poder são um exemplo claro disso. O que é preciso ressaltar é a capacidade do poder de encontrar-se não apenas de maneira omnipresente, mas indistinguível dos fenômenos que só existem na medida em que são transpassados por tais relações. Dessa forma, não existe na economia, na sexualidade, na subjetividade dos indivíduos ou em qualquer instituição social, algum tipo de pureza ou independência. A economia só existe na medida em que indivíduos fazem escolhas e utilizam-se de discursos para legitimar tais escolhas, força para afastar as ações indesejáveis e influência para atrair as desejáveis. A sexualidade não possui apenas um viés biológico, mas completamente político e social, na medida em que propõe interditos, encoraja alguns comportamentos, cria desejos, influencia padrões estéticos, dentre outras possibilidades.

Nem mesmo nossa subjetividade é autônoma e exterior as relações de poder. Podemos constatar isso historicamente, na medida em que a cada período histórico, cada grande mudança nas relações de poder de uma sociedade, abre as portas para a constituição de sujeitos completamente diferentes. O sujeito da Antiguidade não é o mesmo da Idade Média, Moderna ou Contemporânea. E isso apenas para citar nos casos em que tal modificações acontecem de maneira macro. Às vezes precisamos de apenas uma estação para que um modo de se vestir se torne obsoleto e o que era belo até então, soe estranho aos olhos. Uma reforma ortográfica e algum tempo depois a palavra "idéia", com acento, parece estranha aos olhos.

Dessa forma, não podemos dividir aquilo que seria uma relação econômica e uma relação de poder, uma relação sexual e uma relação de poder, e assim por diante. Não existem relações puras que não sejam permeadas pelo poder. Negar a exterioridade é quase que literalmente afirmar sua omnipresença.

Em terceiro lugar, constatamos com Foucault que o poder vem de baixo, ou seja, não é proveniente de uma matriz única, centralizada, que impõe uma oposição binária entre dominantes e dominados. Isso não significa que o poder não possa assumir uma forma centralizada e que não existam indivíduos que dominem e indivíduos que sejam dominados. Significa apenas que a centralização do poder em um foco é uma ilusão possibilitada pela ausência de ênfase nas inúmeras micro-relações que permitem a existência desta matriz. O Estado não é uma instância que emana por si só algum tipo de poder místico presente por si mesmo, mas um emaranhado de instituições que, por sua vez, são compostas por indivíduos, todos estes em relações, influenciando incessantemente a conduta um dos outros. Como já visto, uma multiplicidade de correlações de forças.

Uma grande dominação, sob esta leitura do poder, é nada mais do que um sistema de homogeneização, cujo sucesso consiste em agrupar estas inúmeras correlações de forças e permitir uma hegemonia detectável, seja na figura de um indivíduo, um grupo de indivíduos ou uma instituição. Mas não são os indivíduos, sozinhos ou aglomerados, que permitem a existência desta dominação, e sim as amplas relações de saber-pode que, ao serem dispostas de maneira homogênea, estabilizam 
assim alguma forma específica de exercício do poder.

Em quarto lugar, talvez o ponto menos claro da análise foucaultiana, temos a ideia de que as relações de poder são intencionais e não-subjetivas. Dizer que as relações de poder são intencionais implica em dizer que elas não se encontram completamente dispersas em um emaranhado amorfo de interconexões desprovidas de sentido. É possível traçar uma linha de análise e investigar qual a "intenção" presente em uma relação de poder qualquer. Podemos dotá-la de significado e interagir com sua intencionalidade. Detectar sua estratégia e utilizar o conhecimento de seu funcionamento para fazer algo a respeito (seja rejeitá-la ou reforçá-la). As relações de poder possuem sempre um objetivo, vão sempre em alguma direção, seguem algum fluxo. Algumas pessoas são beneficiadas e outras prejudicadas. Jamais encontraremos uma instância neutra capaz de isentar completamente as relações de poder de seu caráter intencional.

Todavia, é preciso prestar atenção ao caráter não-subjetivo das mesmas. Isso significa dizer que as relações de poder não são nunca o fruto isolado da subjetividade de algum indivíduo (ou de um grupo de indivíduos). Precisamos lembrar aqui o caráter complexo no qual o poder é uma multiplicidade de correlações de forças, mas a subjetividade dos indivíduos também é fruto deste processo. Frequentemente, alguma formatação do poder que adquiriu certa homogeneidade, estabilidade ou hegemonia, parece fruto da invenção deliberada de sujeitos racionais. Dizer que as relações de poder são não-subjetivas é negar parcialmente esta possibilidade. É verdade que indivíduos ou grupos podem manipular as relações de poder de acordo com seus interesses próprios. Mas também é verdade que estes próprios interesses já são provenientes destas relações e que tal manipulação só existe dentro de um sistema já dado, formulado por outras pessoas em outros tempos, que por sua vez, só se tornou possível em um sistema histórico complexo e contingente. A subjetividade é um elemento das relações de poder, mas as mesmas são não-subjetivas.

Talvez a questão fique mais clara com um exemplo. Tomemos a homofobia, o racismo ou a misoginia, entendidos aqui como formulações do poder provenientes de um longo contexto histórico. Se é verdade que indivíduos podem ser, em suas subjetividades, homofóbicos, racistas ou misóginos, também é verdade que em momento algum, tais sistemas são invenção deles. O patriarcado, por exemplo, é fruto de uma série de acontecimentos contingentes que foram interpretados e reinterpretados inúmeras vezes ao longo de nossa história, e precisou de um número incontável de relações de poder para operacionalizar sua existência. $\mathrm{O}$ patriarcado é um sistema que busca homogeneidade, possui uma intencionalidade é conta com inúmeras subjetividades para existir. Contudo, o patriarcado é não-subjetivo, não foi idealizado por uma subjetividade, é fruto de uma complexa rede de relações transversais de saber e poder, estáveis em alguns contextos, instáveis em outros.

Como complemento, para elucidarmos definitivamente esta que talvez seja a mais complexa das considerações sobre o poder feitas por Foucault, a seguinte passagem nos parece bastante esclarecedora:

Mas se você me pergunta: esta nova tecnologia de poder historicamente teve origem em um indivíduo ou em um grupo determinado de indivíduos que teriam decidido aplica-la para servir a seus interesses e tornar o corpo social passível de ser utilizados por elas, eu responderia: não. Estas táticas foram inventadas, organizadas a partir de condições locais e de urgências particulares. Elas se delinearam por partes antes que uma estratégia de classe as solidificasse em amplos conjuntos coerentes. (2010c, p. 221/222).

Por último, em quinto lugar, Foucault reconhece que onde há poder, há resistência. De fato, as relações de poder são imanentes aos dispositivos (ou as 
estruturas) em que se encontram. Não é possível separar o poder daquilo que só existe através dele. Isso significa, todavia, em dizer que a própria resistência é imanente ao poder. Todas as relações de poder pressupõem a existência de relações de resistência, ainda que bastante tímidas, com sua concretude se encontra apenas em caráter de potência. Pressupor uma relação de poder é pressupor uma resistência imanente a ela. Resistir é operacionalizar e tornar real a resistência concebível em cada relação. Não existe um poder que não poderíamos resistir, porque impossível ou ilegítimo. Estar em uma relação de poder é estar em uma relação que poderia ser diferente do que é.

Acreditamos que todas estas considerações sobre o poder reforçam o seu caráter omnipresente e ajudam a explicar melhor o seu funcionamento. Entretanto, certamente alguns questionamentos irão surgir. Como fica a liberdade neste contexto? Se tudo é poder, não estamos em uma condição cíclica na qual qualquer mudança seria irrelevante? Antes de tratar esta questão, precisamos investigar a anarqueologia e a filosofia analítica da política, de Foucault.

\section{A ANARQueologia e A Legitimidade do PODER}

Em seu curso ministrado no Collège de France, intitulado Do governo dos vivos, problematizando o vínculo existe entre o exercício do poder e a manifestação da verdade na forma de subjetividade, Foucault faz algumas considerações sobre o conceito de ideologia. Nas críticas à ideologia, é costumeiro dizer que quanto mais preocupados com a salvação no outro mundo, mais governáveis são os homens. Nesta análise tradicional, trata-se de desvendar o que um sujeito que se submete voluntariamente ao vínculo com a verdade pode dizer, contra ou a favor, do poder que o sujeita sem que ele deseje. Ou melhor, o que podemos entender a partir de um vínculo voluntário com a verdade que implica em um vínculo involuntário com o poder.

Foucault tenta inverter a questão da ideologia. Agora, trata-se de partir do vínculo involuntário do poder para tentar entender o vínculo voluntário com a verdade, ou melhor, "o que o questionamento sistemático, voluntário, teórico e prático do poder tem a dizer sobre o sujeito de conhecimento e sobre o vínculo com a verdade pelo qual, involuntariamente, ele é mantido? (FOUCAULT, 2014c, p. 71). Dessa forma, podemos dizer que as preocupações de Foucault para com a verdade não seguem um viés epistemológico puro. Foucault não está preocupado em estabelecer critérios para diferenciar o verdadeiro do falso. Sua preocupação é predominantemente política, na medida em que busca questionar as relações de poder necessárias para que aceitemos algo como verdadeiro. Dentre os motivos pelos quais aceitamos algo como verdadeiro ou falso, nunca temos apenas razões racionais, lógicas, epistemológicas e científicas. Enfatizamos aqui que o poder está em permanente interdependência com o saber.

Embora talvez seja possível rastrear uma tese foucaultiana sobre o poder, gostaríamos de ressaltar que a questão funciona muito melhor em termos de atitude. Uma atitude muito próxima de uma postura cética, mas cujo núcleo não consiste exatamente na suspensão do juízo, das certezas e garantias. Uma atitude que consiste em afirmar que nenhum poder é incontestável ou inevitável, não precisamos aceitar previamente nenhuma relação de poder. Para Foucault, "não há legitimidade intrínseca do poder". (2014c, p. 72). Nenhum poder é fundado no direito ou na necessidade. Todo poder é contingente. Foucault rompe com toda uma tradição e propõe uma nova problemática, que visa a abrir as portas para decidirmos que podemos saber e fazer agora que descobrimos que "o contrato social é um blefe e a sociedade civil uma história para criancinhas, que não há nenhum direito universal imediato e evidente que possa em toda parte e sempre sustentar uma relação de poder, qualquer que seja." (FOUCAULT, 2014c, p. 72). 
Importante esclarecer: não se trata de anarquia. A anarquia se sustenta na tese de que o poder é essencialmente ruim e que a solução seria constituirmos uma sociedade em que as relações de poder seriam abolidas completamente. Isso seria impossível uma vez que constatamos que, em Foucault, o poder é omnipresente. Foucault não acredita que todo poder é ruim, e sim que todo poder é questionável, nenhum poder é intrinsecamente legítimo e ninguém o detém como uma propriedade. Dessa forma, a posição de Foucault é definida por ele como sendo uma "anarqueologia". Temos aqui um jogo de palavras com o conceito de anarquia, que coloca em jogo a legitimidade de qualquer relação de poder; e o conceito de arqueologia, utilizado por Foucault como um método para avaliar a história de algum tipo de saber que se deseja compreender melhor, buscando não sua verdade intrínseca, mas como foi possível que o mesmo tenha se constituído historicamente enquanto saber.

Para exemplificar melhor, podemos contrastar o que seria uma análise da loucura em termos de ideologia, e uma análise anarqueológica, presente em História da Loucura. Uma análise em termos de ideologia partiria da loucura como algo dado, que estaria em contraste com a natureza humana, a essência do homem não alienado ou a liberdade fundamental, e buscaria entender as relações de saber que tornaram possível o encarceramento de alguns indivíduos. Uma análise em termos anarqueológicos tentaria entender o encarceramento em sua singularidade histórica, recusando partir de algum "universal" que pudesse nos dizer "o que é a loucura". Nas palavras do autor:

Tratava-se de não partir de nenhuma posição humanista dizendo: eis o que é a natureza humana, eis o que é a essência humana, eis o que é a liberdade humana. Era preciso considerar a loucura um $\mathrm{x}$ e se apropriar da prática, somente da prática, como se não se soubesse nada e fazendo de modo a não saber nada sobre o que é a loucura. E era a partir daí que se tratava de procurar que tipo de relações de conhecimento se achava por essa prática mesma, fundado, com seus efeitos estruturantes e determinantes, no campo do saber, da teoria, da medicina, da psiquiatria, mas também com seus efeitos na experiência do próprio sujeito quanto à disjunção entre razão e desrazão, seja o sujeito considerado doente ou não. (2014c, p. 73/74).

Esta apropriação da prática sem pressupor universal algum pode soar contra intuitiva. De fato, frequentemente fez com que muitos acreditassem que Foucault estaria negando a existência da loucura, como podemos ver na seguinte passagem de Paul Veyne:

Mal compreendida, esta concepção da verdade como não correspondência com o real fez crer que, segundo Foucault, os loucos não eram loucos e que falar de loucura era ideologia; até mesmo um Raymond Aron não compreendia diferentemente a História da Loucura e dizia-me sem rodeios: a loucura não é senão demasiado real, basta ver um louco para sabê-lo, protestava ele, e tinha razão; o próprio Foucault professava que a loucura, por não ser aquilo que dela disse, diz e dirá o respectivo discurso, nem por isso "era nada". (2014, p. 12).

Contestar a loucura enquanto um "Universal" não consiste em negar a sua concretude, sua realidade, sua existência nua e crua. Trata-se, antes de tudo, de aceitar que só temos "loucura" na medida em que criamos todo um sistema racional, com expectativas de comportamentos culturais, cognitivos, psicológicos e racionais, capazes de incluir e excluir indivíduos, nomeando-os como loucos e sãos. Primeiro temos as inúmeras relações de poder concretas que permitem a existência destes dispositivos que podem, apenas posteriormente, ser examinados e inseridos em um discurso significativo. 


\section{A Filosofia analítica da política}

Foucault inicia seu artigo intitulado A filosofia analítica da política (1978), constatando que o século XX conheceu duas doenças do poder: o fascismo e o stalinismo. Embora tais sistemas tenham levado o poder a dimensões até então desconhecidas, Foucault alega que precisamos admitir que nazismo e stalinismo "apenas fizeram prolongar toda uma série de mecanismos que já existiam nos sistemas sociais e políticos do Ocidente." (2006b, p. 37). Não criaram uma nova lógica do poder, mas radicalizaram uma já existente.

Uma das funções mais tradicionais e antigas do filósofo no Ocidente, segundo Foucault, era a de colocar limites no poder, ou seja, exercer a função de antidéspota. Sólon fora o legislador que deveria definir os limites legais do poder; Platão tentou ser o conselheiro/pedagogo do Príncipe em suas viagens à Sicília; os cínicos se mantiveram independentes ao poder, a despeito de qualquer abuso, servindo como um exemplo a ser seguido. Para Foucault, o papel de moderação ao poder ainda merece ser desempenhado nos dias atuais.

Todavia, a despeito deste papel de moderação do poder, Foucault alerta que a partir do século XVIII, o ocidente passa a experimentar algo que nunca havia experimentado antes: um Estado Filosófico. Foucault entende um Estado Filosófico como um Estado que se baseia em uma forma de pensamento que, ao refletir sobre o mundo, designa a si mesmo o poder de prescrever a estrutura do Estado, as relações sociais e as condutas individuais. A partir da Revolução Francesa, passamos a presenciar regimes políticos que possuem relações orgânicas com alguns sistemas filosóficos, como o caso da própria Revolução e do Império Napoleônico com Rousseau; o estado prussiano com Hegel; e o estado hitlerista com Nietzsche. Foucault constata que isso é paradoxal, na medida em que não são elementos que estavam previstos na filosofia de tais pensadores e tampouco eram desejados pelos mesmos.

O século XIX é definido por Foucault então como o século dos Estados filosóficos, ou seja, o século dos Estados "que se organizam e definem suas escolhas fundamentais a partir de proposições filosóficas, dentro de sistemas filosóficos e como verdade filosófica da história". (2006b, p. 40). É surpreendente e perturbador, para Foucault, o fato de que todas estas filosofias que se tornaram Estado, eram, sem exceção, filosofias da liberdade. A grande contradição aqui consiste no fato de que tais filosofias da liberdade instituíram o oposto da liberdade, através de formas de poder baseadas na burocracia ou no terror. Quanto mais a sério os filósofos da liberdade foram levados, mais foram usados para autorizar formas excessivas de poder.

O objetivo de Foucault é ultrapassar tanto a filosofia em sua função antidespótica, quando em sua função de prescritora da liberdade. Precisamos de uma filosofia que se recuse a impor sua própria lei ao poder. Que deixe de pensar em si mesma como profecia, pedagogia ou legislação e passe a exercer um papel de contrapoder. O papel da filosofia deveria ser, a partir de então, o de tornar visível e intensificar as lutas em torno do poder, elucidando as estratégias e esclarecendo os focos de resistência. Nas palavras do autor:

Há muito tempo se sabe que o papel da filosofia não é descobrir o que está escondido, mas sim tornar visível o que precisamente é visível - ou seja, fazer aparecer o que está tão próximo, tão imediato, o que está tão intimamente ligado a nós mesmos que, em função disso, não o percebemos. Enquanto o papel da ciência é fazer conhecer aquilo que não vemos, o papel da filosofia é fazer ver aquilo que vemos. Desse ponto de vista, a tarefa da filosofia atualmente bem poderia ser: quais são as relações de poder às quais estamos presos e nas quais a própria filosofia, pelo menos há 150 anos, está paralisada? (FOUCAULT, 2006b, p. 42/43). 
O nome do artigo A filosofia analítica da política é um paralelo traçado pelo autor à filosofia analítica anglo-saxônica que se propõe a refletir sobre as estruturas profundas da língua, pensando no uso cotidiano que se faz dela nos diferentes discursos. De maneira análoga, Foucault propõe a filosofia política como uma análise das relações de poder cotidianas, visando diagnosticar seus objetivos, sejam eles explícitos ou implícitos. Assim, a "filosofia analítico-política" teria como objetivo principal analisar aquilo que Foucault chama de "jogos de poder". De fato, se examinarmos suas principais obras, como a História da Loucura, Vigiar e Punir, História da Sexualidade, entre outras, podemos constatar que foi exatamente isto que fez o autor ao longo das décadas.

A filosofia como um contrapoder não deve ser entendida como uma filosofia que se opõe a todas as formas de poder. Como já visto, isso seria impossível, devido a já comentada omnipresença do poder. Se as relações de poder são imanentes as práticas em que se encontram, eliminá-las por completo é uma impossibilidade que implicaria em eliminar a existência das próprias práticas. Não existe loucura, sexualidade, instituições sociais, sistemas penais e até mesmo qualquer tipo de cultura, sem relações de poder, que por sua vez, encontram-se em estado de interdependência com as relações de poder e possuem, imanentes a si, potencialidades de resistência. Dessa forma, a filosofia como contrapoder tem o papel de articular a compreensão das relações de poder. O objetivo real de uma relação de poder não é necessariamente o seu objetivo declarado. O saber é frequentemente com a finalidade de buscar legitimação, independentemente da realidade nua e crua do poder servir a propósitos completamente diferentes.

Se tomarmos Vigiar e Punir como exemplo, Foucault nos mostra como o ocidente desenvolveu técnicas disciplinares bastante complexas e eficientes para constituir corpos dóceis e obedientes. A prisão é entendida, neste contexto, como a instituição na qual o poder disciplinar está mais evidente e radicalizado. Todavia, as fábricas, as escolas, os exércitos e inúmeras outras instituições sociais também se encontram repletas de técnicas disciplinares. O discurso de legitimação da prisão se dá em termos humanistas, mas sua realidade é predominantemente disciplinar. Dessa forma, enquanto o poder se legitima por uma via, encontra sua finalidade em outra. $\mathrm{O}$ papel da filosofia é fazer aparecer isto que já está visível (as pessoas já sabem que as prisões não ressocializam os indivíduos, por exemplo).

\section{LIBERDADE E OMNIPRESENÇA}

A partir de uma filosofia analítica da política, fundamentada por uma visão anarqueológica do poder, na qual as relações de poder só podem ser consideradas legítimas na medida em que se referem ao consentimento autônomo, esclarecido e sempre provisório dos indivíduos, podemos revisitar a definição foucaultiana de poder, tendo em vista textos posteriores, nos quais às demandas de liberdade aparecem de maneira muito mais clara.

Como já visto, Foucault rejeita uma visão soberana do sujeito, na qual sua constituição se dá de maneira autônoma. Um sujeito é sempre fruto dos dispositivos que atuantes sobre ele desde seu nascimento. Contudo, isso não significa dizer que o autor reduz o sujeito à uma mera passividade. De fato, o modo como se dão as relações de poder permitem constatarmos uma relação entre práticas de sujeição e resistência às mesmas práticas. A subjetividade é o resultado desta tensão. Foucault identifica três formas históricas tradicionais pelas quais os sujeitos são objetivados: 1) O tipo de investigação que tem como objetivo atingir o estatuto de ciência. 2) A objetivação do sujeito em práticas divisoras (louco e o são, criminosos e "bons meninos"). 3)A maneira 
pela qual um ser humano se torna sujeito.

$\mathrm{O}$ autor de Vigiar e punir dá o nome de "antagonismo das estratégias" à sua tentativa de investigar o poder através de suas resistências. A recusa de aceitar as relações de poder estratificadas socialmente pode assumir várias formas históricas. Em $O$ sujeito e o poder, o Foucault analisa uma série de lutas atuais (na medida em que busca uma ontologia do presente), identificando uma série de características importante às mesmas.

1) São lutas transversais que não se limitam à um país. 2) Seus objetivos são os efeitos de poder enquanto tal. 3) São lutas imediatas. Elas não objetivam o "inimigo mor", mas o inimigo imediato. Não visam a uma solução no futuro, como uma revolução, sendo, de certa forma, lutas anárquicas. 4) Questionam o estatuto do indivíduo, na medida em que firmam o direito de ser diferente e enfatizam as individualidades (lutando contra aquilo que Foucault chama de "governo da individualização"). 5) São lutas que se colocam como uma oposição aos efeitos de poder relacionados ao saber, questionando a maneira como o saber circula e suas relações com o poder. 6) Todas essas lutas contemporâneas giram em torno da questão: "quem somos nós", recusando a violência econômica e ideológica, que ignora nossas individualidades e nos propõe uma investigação científica supostamente capaz de determinar aquilo que somos. Neste sentido, a palavra "sujeito" pode ser investigada sob duas perspectivas:

Há dois significados para a palavra sujeito: sujeito a alguém pelo controle e dependência, e preso à sua própria identidade por uma consciência ou auto reconhecimento. Ambos sugerem uma forma de poder que subjuga e torna sujeito a". (FOUCAULT, 1995, p. 235).

Podemos ver claramente como nem todo "assujeitamento" do indivíduo se dá por vias diretas, nas quais o controle alheio que nos torna dependente assume o papel de principal instrumento de dominação. Foucault também aceita que nossa própria identidade, nossa própria consciência e a forma como nos auto-reconhecemos, pode ser uma forma de sermos subjugados. Dessa forma, na medida em que ressalta a existência de três tipos predominantes de lutas - as lutas contra as formas de dominação, as lutas contra as formas de exploração e as lutas contra as formas de subjetivação - Foucault ressalta à terceira. Sem menosprezar as lutas contra à dominação e a exploração, Foucault alega que o surgimento do Estado, a partir do século XVI, integrou à antiga técnica cristã do poder pastoral às suas instituições. $O$ poder pastoral é uma forma de poder que não ignora a existência e a individualidade dos sujeitos, mas se utiliza dela para governar.

Não acredito que devêssemos considerar o "Estado moderno" como uma entidade
que se desenvolveu acima dos indivíduos, ignorando o que eles são e até mesmo
sua própria existência, mas, ao contrário, como uma estrutura muito sofisticada,
na qual os indivíduos podem ser integrados sob uma condição: que a esta
individualidade se atribuísse uma nova forma submetendo-a a um conjunto de
modelos muito específicos. (FOUCAULT, 1995, p. 237).

A individualidade dos seres humanos deve ser integrada a modelos específicos de subjetividade. O governo por subjetivação é um desafio a ser enfrentado: "Talvez o objetivo hoje em dia não seja descobrir o que somos, mas recusar o que somos." (FOUCAULT, 1995, p. 239). Assim, não se trata tanto de nos libertarmos do Estado enquanto instituição, mas das formas de subjetivação que ele frequentemente tenta nos impor. Temos de promover novas formas de subjetividade através da recusa deste tipo de individualidade que nos foi imposto há vários séculos." (FOUCAULT, 1995, p. 239). De acordo com John Rajchman: 
A subjetividade é política para Foucault mais exatamente por causa de procedimentos concretos de "subjetivação" - procedimentos através dos quais passamos a reconhecer-nos como sujeitos de uma forma de experiência que se funda num corpo de conhecimento, normas e modelos de nossa natureza. A política da subjetividade de Foucault não começa com uma autonomia ideal como padrão de crítica, mas com uma análise das formas históricas da constituição do sujeito. (RAJCHMAN, 1987, p. 74).

O poder enquanto dominação e exploração pode ser bastante problemático, todavia, o poder enquanto forma de subjetivação apresenta uma esfera mais delicada, na medida em que frequentemente o confundimos com liberdade. A omnipresença do poder em Foucault se mostra bastante presente, no momento em que até mesmos nossas crenças, desejos e projetos são fruto de uma forma de poder que pode ser proveniente de instituições que se utilizam de dispositivos pastorais para orientar nossas experiências em direção a alguns interesses específicos de um grupo específico de cidadãos.

Neste contexto, uma relação de poder se distingue da violência (que age sobre um corpo e encontra apenas o polo da passividade), sendo melhor entendido como pertencente ao âmbito das formas de governo. "Ele [o poder] é um conjunto de ações sobre ações possíveis." (FOUCAULT, 1995, p. 243). Trata-se então, da possibilidade de conduzir condutas (e não do enfrentamento direto entre dois adversários). Nas palavras do autor:

O modo de relação próprio ao poder não deveria, portanto, ser buscado do lado da violência e da luta, nem do lado do contrato e da aliança voluntária (que não podem ser mais do que instrumentos); porém, do lado deste modo de ação singular - nem guerreiro nem jurídico - que é o governo. (FOUCAULT, 1995, p. 244).

Ao definir o poder como uma ação sobre a ação dos outros, ou como governo dos homens, podemos constatar que uma dimensão se destaca: a liberdade. Segundo o filósofo de Poitiers, "O poder só se exerce sobre "sujeitos livres" enquanto "livres"." (FOUCAULT, 1995, p. 244). Na escravidão, ou em outros contextos nos quais as relações estão saturadas, não temos relações de poder, mas de violência e coação. $\mathrm{Na}$ medida em que a liberdade passa a ser um pré-requisito ao poder, vemos seu caráter agonista ser ressaltado. O poder é uma provocação permanente, uma incitação recíproca. A liberdade é sua condição de existência.

De acordo com Johanna Oksala em Foucault on Freedom, a crítica de Foucault à primazia do sujeito reside na ideia central de que o sujeito "não é o agente das mudanças sociais ou epistêmicas, mas o efeito delas. Não existe sujeito em si anterior à codificação cultural normalizadora que transforma os seres humanos em sujeitos." (OKSALA, 2005, p. 1, tradução nossa). Isso levaria seus críticos a concluírem que a negação deste sujeito autônomo implicaria na negação de qualquer concepção significativa de liberdade. Se não possuímos uma subjetividade autêntica a ser liberdade, se somos frutos de disciplinas, libertar-nos delas não nos emanciparia, mas aprisionaria nossas subjetividades em outros códigos e disciplinas. Desta forma, a ideia de que não existe liberdade em Foucault é proveniente de uma má leitura do aspecto omnipresente do poder.

É verdade que não estamos alheios às práticas e relações de poder que presentes no contexto em que estamos inseridos. Nossas subjetividades são sim frutos de 
inúmeras relações que nos escapam. Contudo, é apenas porque projetamos um ideal de liberdade e emancipação essencialista que consideramos insuficiente a liberdade proveniente das nossas relações interconectadas. Quando define a liberdade como prérequisito do poder, Foucault está respondendo indiretamente a seus críticos insatisfeitos. Não somos livres devido a alguma instância na qual podemos repousar em nossa liberdade, mas apenas na medida em que estamos perpetuamente em relações que, se por um lado, tentam subjugar nossas subjetividades, por outro, são frequentemente influenciadas por elas e raramente conseguem suprimir todos os meios de resistência (e quando conseguem, já não podemos mais chamar de relações de poder).

Dessa forma, é justamente por estarmos permanentemente em relações de poder que somos livres. Tais relações, por pressuporem sempre uma resistência imanente, por serem não-subjetivas, por terem a liberdade como condição de existência, por permitirem a filosofia como uma prática constante de antidespotismo, dentre outras características, permitem uma liberdade mais real, tangível, que não precisa se sustentar em pressuposições ontológicas idealistas, mas reside na prática concreta das relações entre indivíduos que são fruto dos dispositivos que lhes circundam e seres livres atuantes nos mesmos.

\section{CONCLUSÃo}

Foucault buscou analisar o poder na medida em que considerou uma tarefa imprescindível para compreendermos os sujeitos, ou melhor, a formação das subjetividades. Neste sentido, o caráter omnipresente do mesmo pode ser interpretado como um beco sem saída, na qual somos apenas frutos de relações arbitrárias, muito além do nosso controle. Em algum grau, isto é verdade. É inegável que os dispositivos aos quais nos encontramos imersos, exercem grande influência em nossas personalidades. Todavia, na medida em que somos seres capazes de agir e interagir com os mesmos, é também através da própria omnipresença das relações de poder que somos capazes de sermos livres.

Nós não somos seres inertes às relações que influenciam nossas subjetividades. Em Foucault, isto nos leva a uma série de implicações políticas a serem levadas em conta. A primeira delas, como já visto, é a premissa anarqueológica, que consiste em não aceitar nenhuma legitimidade intrínseca ao poder, exceto aquelas que podemos desejar e justificar em termos que considerem completamente quem somos e aqueles que estão à nossa volta. $\mathrm{O}$ poder não se justifica por si só. Se o poder está em todo lugar, isso não significa que não podemos mudar suas configurações conforme nossos interesses. A segunda premissa, presente na filosofia analítica da política, é a de que a filosofia possui um papel de contrapoder a ser exercido. Se encontramos nossa liberdade na possibilidade de resistir às subjetividades que nos são impostas, então a filosofia pode ser entendida como uma prática de liberdade. Resistir ao poder é, de certa forma, tomar as rédeas de nossa subjetividade. Temos em Foucault uma concepção que dispensa completamente qualquer essencialismo, em prol de uma concepção na qual o poder se encontra imerso em todas as nossas outras relações, e justamente por isso somos livres.

A ideia de que o poder é omnipresente, é frequentemente vista como algo negativo, inclusive, como se o próprio Foucault tivesse uma visão pejorativa do poder, a ponto de quase transformá-lo em uma entidade que, por englobar tudo, não nos daria sossego e controlaria todas as nossas ações. A seguinte passagem de Richard Rorty nos mostra bem essa visão:

Em seu uso foucaultiano, termo "poder" denota uma agência que tem deixado uma mancha indelével sobre toda palavra em nossa língua e sobre toda instituição 
em nossa sociedade. Ela sempre estará lá, mas não se pode vê-la chegando ou partindo. Alguém pode ver um portador de propina de alguma corporação chegando no escritório de um deputado, e talvez a tese possa impedi-lo de entrar. Mas ninguém pode impedir o poder, no sentido de Foucault. O poder está tanto dentro quanto fora de alguém. (1999, p.131).

É neste sentido que, ainda com Rorty, o poder em Foucault é algo extremamente perverso. "A ubiquidade do poder foucaultiano reminiscente da ubiquidade de Satã, e assim da ubiquidade do pecado." (RORTY, 1999, p. 131). Desta forma, neste artigo, buscamos trazer elementos que nos permitam nos desvincularmos deste tipo de visão.

$\mathrm{O}$ objetivo principal deste artigo foi mostrar que podemos encontrar em Foucault, senão uma visão positiva do poder, ao menos uma visão que suficientemente neutra para que ele possa ser entendido como uma série de relações que podem ter consequências tanto positivas quanto negativas. Não existe legitimidade prévia ao poder, mas podemos estar inseridos em relações nas quais legitimamos ou resistimos à tais relações. Podemos usar a filosofia para analisar às mesmas, explorando assim seu potencial de contrapoder. A omnipresença do poder significa que frequentemente o poder irá iniciar relações de dominação, mas também que fará o mesmo com relações de liberdade. O problema não consiste em ser ou não uma relação de poder, mas em se dar em termos de dominação ou emancipação, violência ou consentimento, controle ou liberdade.

\section{REFERÊNCIAS}

FOUCAULT, Michel. Vigiar e Punir: História da violência nas prisões. 32. ed. Tradução de Raquel Ramalhete. Petrópolis: Vozes, 1987. História da Sexualidade 1: A vontade de Saber. 11. ed. Tradução de Maria Thereza da Costa Albuquerque e J.A. Guilhon Albuquerque. Rio de Janeiro: Graal, 1988a. O sujeito e o Poder. In: DREYFUS, Hubert; RABINOW, Paul. Michel Foucault: Uma trajetória Filosófica: Para além do Estruturalismo e da Hermenêutica. Tradução de Vera Porto Carrero. Rio de Janeiro: Forense Universitária, 1995.

Ética, sexualidade, política: Ditos e escritos. Vol. V, 2. ed. Tradução de Elisa Monteiro e Inês Autran Dourado Barbosa. Rio de Janeiro: Forense Universitária, 2006. Repensar a política: Ditos e escritos. Vol. VI. Tradução de Ana Lúcia Paranhos

Pessoa. Rio de Janeiro: Forense Universitária, 2010.

Do governo dos vivos. Curso no Collège de France (1979-1980). Tradução de Eduardo Brandão. São Paulo: Wmf Martins Fontes, 2014.

OKSALA, Johanna. Foucault on Freedom. New York: Cambridge University Press, 2005.

RAJCHMAN, John. Foucault: A liberdade da filosofia. Tradução de Álvaro Cabral. Rio de Janeiro: Jorge Zahar, 1987.

RORTY, Richard. Para realizar a América: O pensamento de esquerda no século XX na América. Tradução de Paulo Guiraldelli Jr, Alberto Tosi Rodrigues e Leoni Henning. Rio de Janeiro: DP\&A, 1999.

VEYNE, Paul. Foucault: seu pensamento, sua pessoa. 2.ed. Tradução de Marcelo Jacques Morais. Rio de Janeiro: Civilização brasileira, 2014.

\section{Notas}

1 "It is not the agent of social or epistemic changes, but rather the effect of them. There is no subject in itself prior to the normalizing cultural coding that turns the human being into a subject". 